\title{
Bluetooth Control Cleaning Robot using Arduino
}

\author{
Mohd. Shahbaz Khan, Nagageetha, M.Gurunadha Babu
}

\begin{abstract}
Main determination of this research is to style the work automatic, scrubbing is a very tough job it requires lot of patience and lot of persons to clean and in cleaning a person may damage his/her healthiness, cleaning is more time taking work.

To do the work easily we have developed the robot \& it is designed in such a way that it can clean house, offices, apartments, cellars, and even streets as well. The person who is standing far gone of the cleaning area is monitoring the robot. This design include of DC motors, servo motor brushes, tub, scrub, LED light, battery, water pump, Arduino and Bluetooth for wireless communication, mobile phone .
\end{abstract}

Keywords - mobile phone ,Android applications, Bluetooth model, DC motor, servo motor, LM293D

\section{INTRODUCTION}

Basic goal of the research paper is to design a robot which decrease the effort of person in scrubbing and sweeping and find solution to overcome drawbacks of the earlier cleaning techniques .In manual process human beings were used as sweepers for sweeping the floor \& roads.

In this process of cleaning people will take much time to complete their work and also people will phase some health problems like back pain, shoulder pains etc.

For the above mention problems scientists invented "Vacuum Cleaner". It is also a cleaning machine. Using this cleaner people are facing some problems like it is heavy to lift, machine that often hard to move in the home. And to move vacuum cleaner up and down stairways is almost challenging. Vacuum cleaner was manufactured in large size. Based on variety of the vacuum cleaner model, our electricity bill will increase from hundreds to thousands rupees

To solve the above mention problems a cleaning robot is designed and develop which is fast and the it can reach the places where person cannot go robot can operated indoors and outdoors. Power utilization is less by using this robot

This robot is designed in such way that it can be use in house, offices, apartments, cellars and even roads . By using this Robot we can mopp easily. It is operated through

Revised Manuscript Received on September 10, 2019.

Mr. Mohd. Shahbaz Khan, Associate Professor , Department of Electronics and Communication Engineering, CMR Institute of Technology, Hyerabad, Telangana, India

(E-mail: hahbazkhan434@gmail.com)

Nagageetha, Assistant Professor, Department of Electronics and Communication Engineering, CMR Institute of Technology, Hyerabad, Telangana, India

(E-mail: geethamamilla14@gmail.com)

Dr.M.Gurunadha Babu, Professor,Department of Electronics and Communication Engineering, CMR Institute of Technology, Hyerabad, Telangana, India

(E-mail: mgurunadhababu@gmail.com) mobile via Bluetooth control. Price of this robot is very less compared to other cleaning technics

It is mainly helpful for physically handicapped people where the person cannot move from one place to another place. Person operating the robot will stay away from the cleaning area while cleaning and person health is saving.

And cost is less

The robot that cleans your house's floor by rotating mops along with servo motor.

There's also water pump and water reservoir which can be switched on when required to throw water on the floor and make the mops moist for a proper clean.

Block Diagram
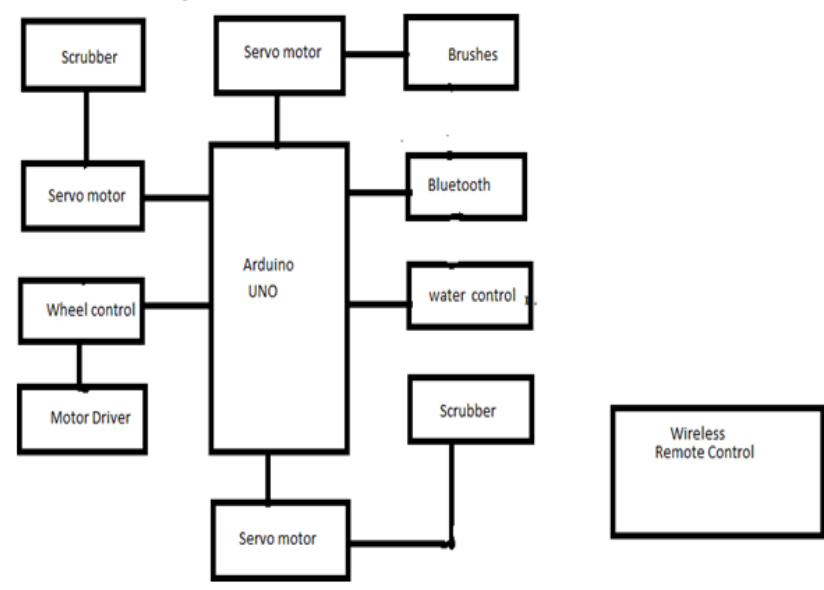

To DC motor the robot wheel are assign and when switch on wheel will rotate and robot will move in forward direction. Servo motor it use for rotation of brushes and scrubbers, Arduino Uno it is microcontroller which will received command from mobile phone.

\section{WORKING}

In this paper, for controlling the robot we are using Bluetooth and it is at the transmitter side and receiver side.

By passing the commands, from mobile phone and maintain minimum prescribed distance by the Bluetooth committee for transfer of information. Based on the instructions robot will starts the working.

The Arduino is a microcontroller board based on the ATmega328. It has 14 digital input/output pins (of which 6 can be used as PWM outputs), 6 analog inputs, a $16 \mathrm{MHz}$ ceramic resonator, a USB connection, a power jack, an ICSP header, and a reset button. In this, robot we are using seven analog input pins and they are 3, 5, 6, 9, 10, 11, 12. 
To start the movement of the robot wheel, DC motor must be on via Bluetooth which is connoted to Arduino and robot will starts moving in forward direction . 9- 12 volts battery power supply is in used

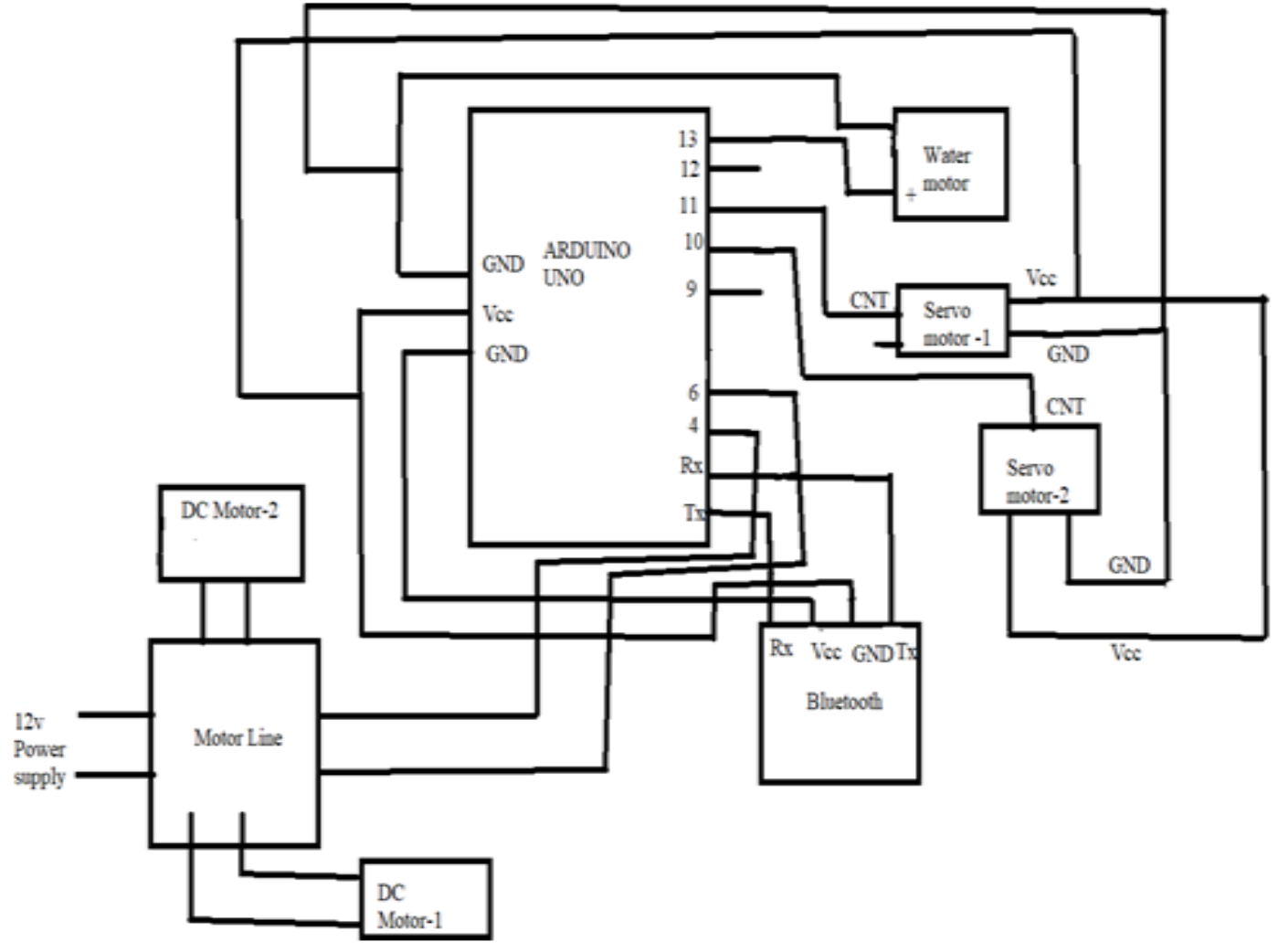

Circuit Diagram

DC motor- 1 positive terminal is connected to pin-10 of Arduino and negative terminal is connected to pin -11 of Arduino. DC motor-2 positive terminal is connected to Arduino pin-9 and negative terminal is connected to Arduino pin-6.

Two servo motors are use . One for performing sweeping operation and another one for performing the cleaning operation. It is controlled with Bluetooth via mobile phone. The servo motor- 1 is coupled to the pin-5 of Arduino, it turns $\mathrm{ON}$, it will starts movement of the servo motor-1 along with the brushes.

Brushes are used for sweeping the floor. So that the sweeping is performed. It can be moved in any angles like forward, backward and side wards. After completion of sweeping process.
It will start cleaning process, it is based on servo motor-2. Fill the tub with water, the water pump which carries the water from the tub and spills it near the scrubber to mop the floor. Water pump is connected to the pin-12 of the Arduino The common ground wire from all the motors has to be coupled to the ground of microcontroller. And it starts the cleaning through the servo motor-2 The servo motor-2 is attached to pin-3 of Arduino

The places which are very dark ,that can be cleaned,we are using LED lights which are present on the robot once the work is done turn off the LED lights.

\section{Flowchart}




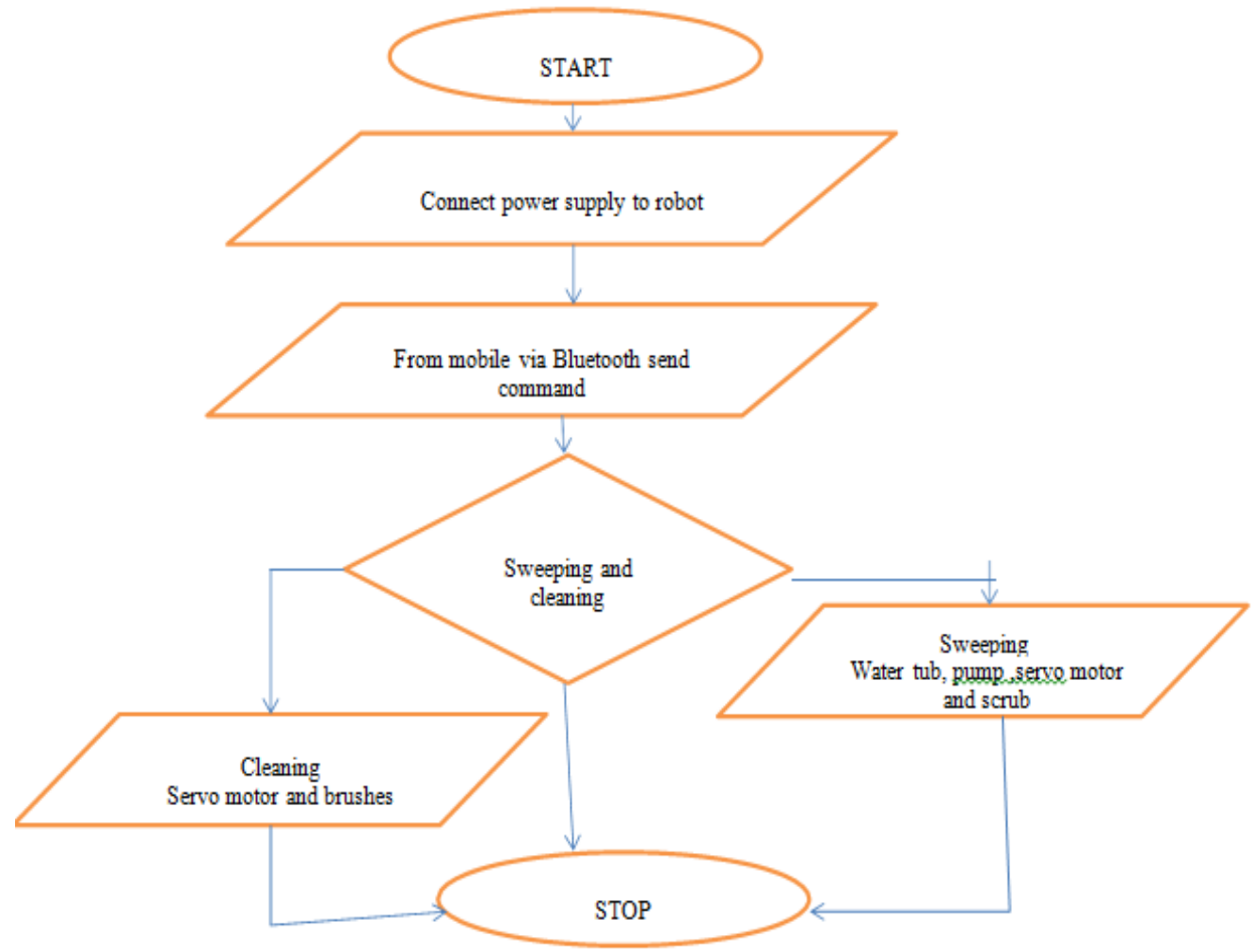

\section{RESULTS}

\section{Result1: Starting point of robot}

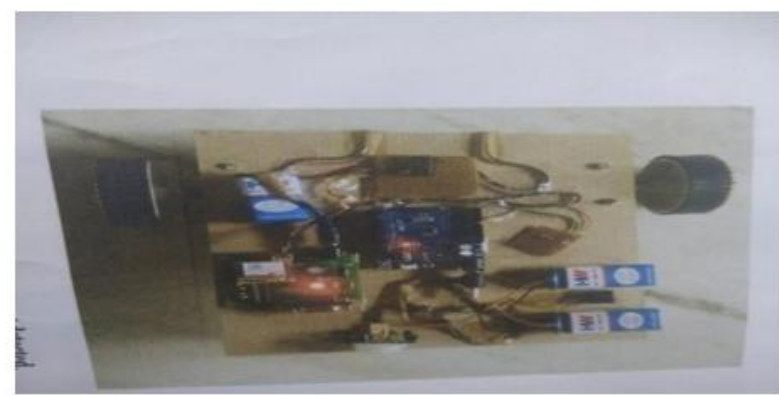

Result 2: Final result of Robot

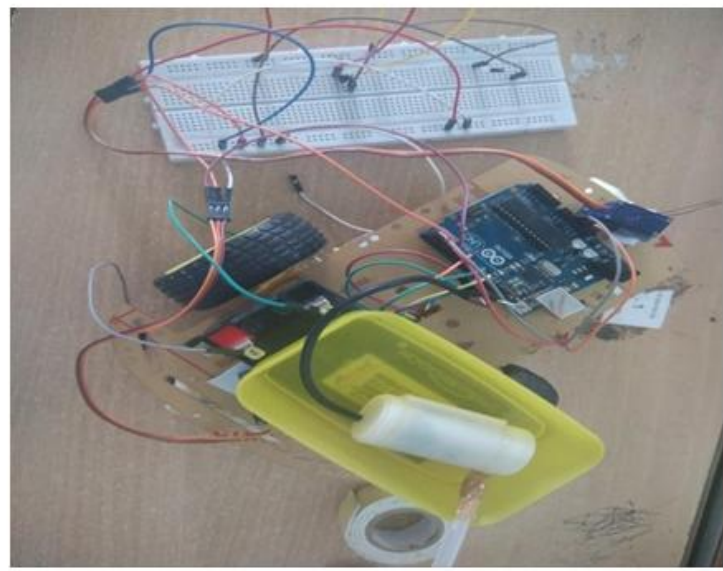

\section{CONCLUSION}

This research paper facilitates effective floor cleaning with sweeping and mopping operations. It reduces the labour cost and saves time also and provides efficient cleaning. Bluetooth module and android application can be used to control the robot

\section{FUTURE SCOPE}

In place Bluetooth technology GSM MODEM will be use and obstacles detection will be added

\section{REFERENCE}

1. Jens-Steffen Gutmann, Kristen Culp, Mario E. Munich and Paolo Pirjanian. The Social Impact of a Systematic Floor Cleaner. In IEEE international workshop on advance robotics and its social impacts, Technische University munchen, Germany May 21-23,2012.

2. J Frolizzi C.Disalvo. Service robots in the domestic environment: A study of Roomba vacuum in the home". In int. conference on human robot interaction HRI, PAGE 258-265 March 2006.

3. H.Asada and J.-J E. Slotin, robot analysis and control, a wiley-interscience publication, 1986, pp. 29-49.

4. Karthick. T. Ravi Kumar. A, Selvakumar. L, Viknesh. T "Simple Autonomous Cleaner Robot" International journal of Science, Engineering \& Technology Research (IJSER), Vol.4. Issue 5 May 2015

5. Uman Khalid, Haseeb Haider, Tahseen Amin Khan Qasuria "Smart Floor Cleaning Robot (CLEAR)" in IEEE standard 2015.

6. Naman Aggrawal, Piyusha Chaudhari, Akshay Mahalkar "Review Paper Based on Cleaning Robot", vol.3 No.5 May 2016.

7. Marneet Kaur, Preeti abrol "Development of floor cleaner robot (Automatic and manual)", July 2014

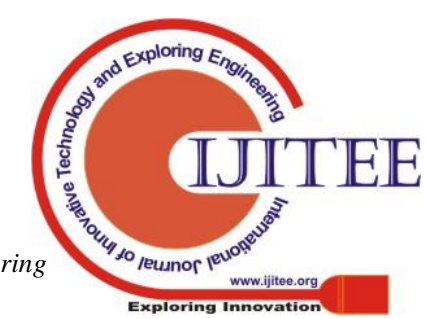

